\title{
What is the purpose of launching World Journal of Biological Chemistry?
}

\author{
Lian-Sheng Ma
}

Lian-Sheng Ma, Beijing Baishideng BioMed Scientific Co., Ltd., Room 903, Building D, Ocean International Center, No. 62 Dongsihuan Zhonglu, Chaoyang District, Beijing 100025, China

Author contributions: Ma LS solely contributed to this paper. Correspondence to: Lian-Sheng Ma, Professor, President and Editor-in-Chief, Beijing Baishideng BioMed Scientific Co., Ltd., Room 903, Building D, Ocean International Center, No. 62 Dongsihuan Zhonglu, Chaoyang District, Beijing 100025,

China.1.s.ma@wjgnet.com

Telephone: +86-10-59080036 Fax: +86-10-85381893

Received: October 20, 2009 Revised: November 20, 2009

Accepted: December 18, 2009

Published online: January 26, 2010

\begin{abstract}
The first issue of World Journal of Biological Chemistry $(W J B C)$, whose preparatory work was initiated on July 01, 2009, will be published on January 26, 2010. The WJBC Editorial Board has now been established and consists of 341 distinguished experts from 37 countries. Our purpose of launching $W J B C$ is to publish peer-reviewed, high-quality articles via an open-access online publishing model, thereby acting as a platform for communication between peers and the wider public, and maximizing the benefits to editorial board members, authors and readers.
\end{abstract}

(C) 2010 Baishideng. All rights reserved.

Key words: Maximization of personal benefits; Editorial board members; Authors; Readers; Employees; World Journal of Biological Chemistry

Peer reviewer: Christine Blattner, $\mathrm{PhD}$, Institute of Toxicology and Genetics, Forschungszentrum Karlsruhe, PO Box 3640, 76021 Karlsruhe, Germany

Ma LS. What is the purpose of launching World Journal of Biological Chemistry? World J Biol Chem 2010; 1(1): 1-2
Available from: URL: http://www.wjgnet.com/1949-8454/full/ v1/i1/1.htm DOI: http://dx.doi.org/10.4331/wjbc.v1.i1.1

\section{INTRODUCTION}

I am very pleased to announce that the first issue of World Journal of Biological Chemistry (World J Biol Chem, WJBC, online ISSN 1949-8454, DOI: 10.4331) will be published on January 26, 2010. The WJBC Editorial Board has now been established and consists of 341 distinguished experts from 37 countries.

The role of academic journals is to exhibit the scientific levels of a country, a university, a center, a department, and even a scientist, and build an important bridge for communication between scientists and the public. As we all know, the significance of the publication of scientific articles lies not only in disseminating and communicating innovative scientific achievements and academic views, as well as promoting the application of scientific achievements, but also in formally recognizing the "priority" and "copyright" of innovative achievements published, as well as evaluating research performance and academic levels. To realize these desired attributes of a journal and create a well-recognized journal, the following four types of personal benefits should be maximized.

\section{MAXIMIZATION OF PERSONAL BENEFITS}

The maximization of personal benefits refers to the pursuit of the maximum personal benefits in a wellconsidered optimal manner without violation of the laws, ethical rules and the benefits of others.

\section{Maximization of the benefits of editorial board members}

The primary task of editorial board members is to give a peer review of an unpublished scientific article via online office system to evaluate its innovativeness, scientific and practical values and determine whether it 
should be published or not. During peer review, editorial board members can also obtain cutting-edge information in that field at first hand. As leaders in their field, they have priority to be invited to write articles and publish commentary articles. We will put peer reviewers' names and affiliations along with the article they reviewed in the journal to acknowledge their contribution.

\section{Maximization of the benefits of authors}

Since $W J B C$ is an open-access journal, readers around the world can immediately download and read, free of charge, high-quality, peer-reviewed articles from WJBC official website, thereby realizing the goals and significance of the communication between authors and peers as well as public reading.

\section{Maximization of the benefits of readers}

Readers can read or use, free of charge, high-quality peerreviewed articles without any limits, and cite the arguments, viewpoints, concepts, theories, methods, results, conclusion or facts and data of pertinent literature so as to validate the innovativeness, scientific and practical values of their own research achievements, thus ensuring that their articles have novel arguments or viewpoints, solid evidence and correct conclusion $^{[1]}$.

\section{Maximization of the benefits of employees}

It is an iron law that a first-class journal is unable to exist without first-class editors, and only first-class editors can create a first-class academic journal ${ }^{[2,3]}$. We insist on strengthening our team cultivation and construction so that every employee, in an open, fair and transparent environment, could contribute their wisdom to edit and publish high-quality articles, thereby realizing the maximization of the personal benefits of editorial board members, authors and readers, and yielding the greatest social and economic benefits.

\section{CONTENTS OF PEER REVIEW}

In order to guarantee the quality of articles published in the journal, WJBC usually invites three experts to comment on the submitted papers. The contents of peer review include: (1) whether the contents of the manuscript are of great importance and novelty; (2) whether the experiment is complete and described clearly; (3) whether the discussion and conclusion are justified; (4) whether the citations of references are necessary and reasonable; and (5) whether the presentation and use of tables and figures are correct and complete.

\section{SCOPE}

The major task of $W J B C$ is to rapidly report the most recent developments in the research by the close collaboration of biologists and chemists in area of biochemistry and molecular biology, including: general biochemistry, pathobiochemistry, molecular and cellular biology, molecular medicine, experimental methodologies and the diagnosis, therapy, and monitoring of human disease.

\section{COLUMNS}

The columns in WJBC will include: (1) Editorial: to introduce and comment on major advances in rapidly developing areas and their importance; (2) Frontier: to review recent developments, comment on current research status in important fields, and propose directions for future research; (3) Topic Highlight: this column consists of three formats, including: (a) 10 invited review articles on a hot topic; (b) a commentary on common issues associated with this hot topic; and (c) a commentary on the 10 individual articles; (4) Observation: to update the development of old and new questions, highlight unsolved problems, and provide strategies for their resolution; (5) Guidelines for Basic Research: to provide Guidelines for basic research; (6) Guidelines for Clinical Practice: to provide guidelines for clinical diagnosis and treatment; (7) Review: to review systemically the most representative progress and unsolved problems, comment on current research status, and make suggestions for future work; (8) Original Article: to report original and innovative findings; (9) Brief Articles: to report briefly on novel and innovative findings; (10) Case Report: To report a rare or typical case; (11) Letters to the Editor: to discuss and reply to contributions published in $W J B C$, or to introduce and comment on a controversial issue of general interest; (12) Book Reviews: to introduce and comment on quality monographs; and (13) Guidelines: To introduce consensuses and guidelines reached by international and national academic authorities on basic research and clinical practice.

\section{REFERENCES}

1 Zhu DM. What is the purpose of literature citation? Science Times, 2009-07-17. Available from: URL: http://www. sciencenet.cn/htmlnews/2009/7/221552.shtm

2 Li ZX. See the "sallying forth" of Chinese scientific and technical journals from the innovative business model of WJG. Zhongguo Keji Qikan Yanjiu 2008; 19: 667-671

3 Xiao H. First-class publications can not do without firstclass editorial talents. Keji Yu Chuban 2008; (3): 192 